\section{Breathlessness in the older patient with repaired Fallot's Tetralogy: not always the heart}

A 58 -year-old obese farmer $\left(\mathrm{BMI}=31.4 \mathrm{~kg} / \mathrm{m}^{2}\right)$ presented with increasing breathlessness and reduced exercise tolerance for 2 years associated with discomfort after meals, increased snoring and daytime sleepiness. Past medical history included multiple repairs for Fallot'sTetralogy (TOF), asthma and kyphosis. Blood tests were normal. ECG showed RBBB (QRSd=154msecs). Echocardiogram revealed normal left ventricle, and mildly dilated well-contracting right ventricle (RV). Chest X-ray (CXR) showed a very large mass in the right hemithorax; a similar but smaller mass at the same site had been seen in 1992 (figures 1 and 2). Subsequent CT abdomen confirmed a large right-sided Morgagni hernia with bowel loops compressing the lung (figure 3). Cardiac catheterisation demonstrated mild residual pulmonary stenosis and regurgitation, normal pulmonary vascular resistance and unremarkable coronaries. Lung function tests were consistent with alveolar hypoventilation. Cardiorespiratory MDT review agreed that the TOF was blameless in this case; a diagnosis of obstructive sleep apnoea and obesity hypoventilation overlap syndrome exacerbated by the Morgagni hernia was made. Treatment with noninvasive ventilation, $20 \mathrm{~kg}$ weight reduction and physiotherapy, effected complete resolution of symptoms.

Morgagni described (1761) herniation of abdominal organs through a parasternal or retrosternal diaphragmatic defect, predominantly on the right side ${ }^{1}$ and rare. ${ }^{2}$ Symptoms are related to the size and content of hernia, and include respiratory distress, infection, chest pain and gastrointestinal symptoms. Treatment is generally surgical. Although, initially contemplated in this case, pulmonologist review at MDT clearly identified the dominant respiratory component with complete resolution of symptoms with medical therapy.

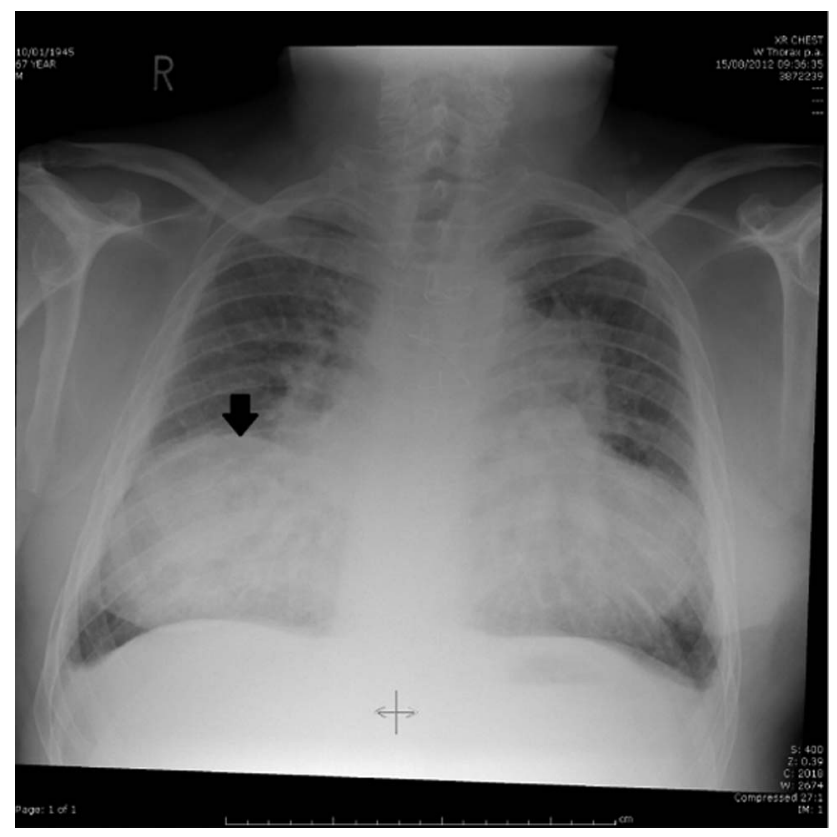

Figure 1 Chest X-ray showing a large mass in the right hemithorax (black arrow).

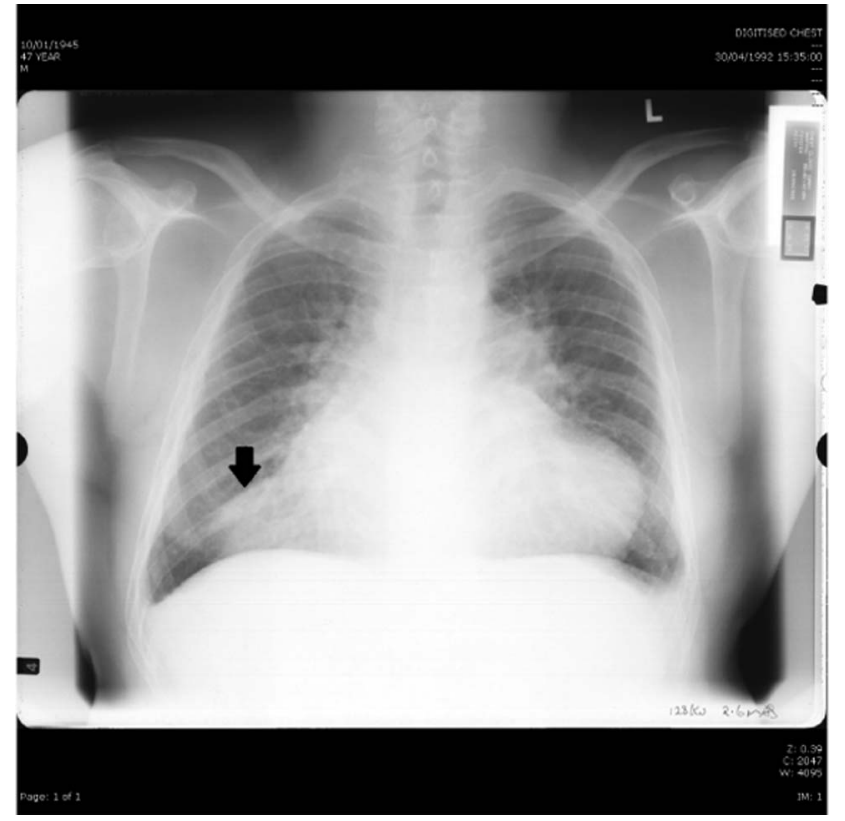

Figure 2 Chest taken 21 years earlier showing a smaller mass in the exact same location in the right hemithorax (black arrow).

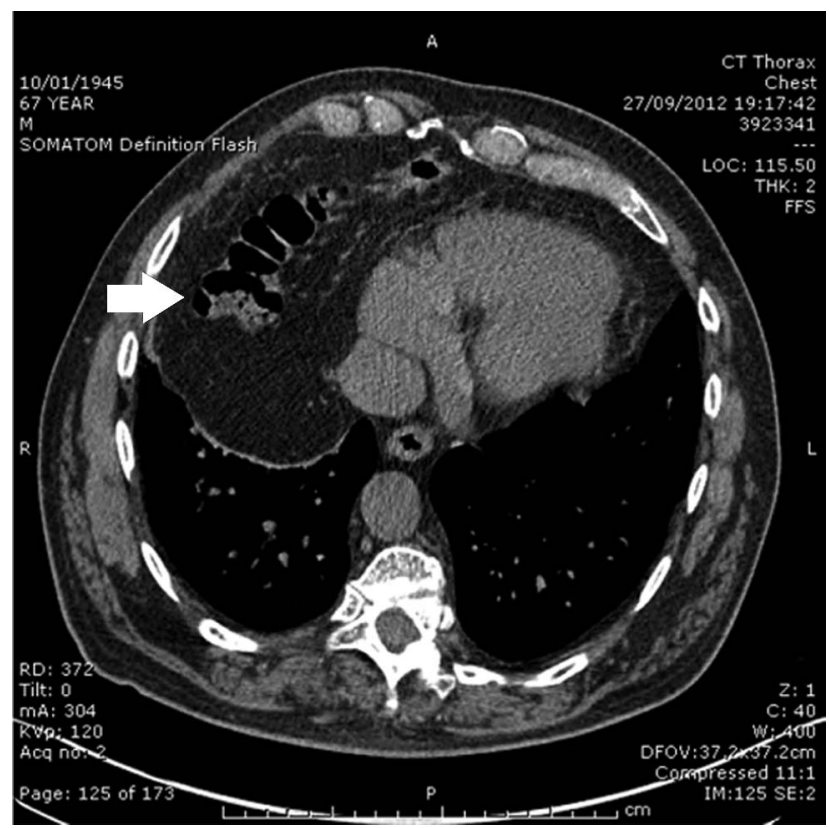

Figure 3 CT scan of the thorax and abdomen showing large bowel loops in the right hemithorax compressing the lung (Morgagni hernia) (white arrow).

\section{Usha Rao, Leisa J Freeman}

Department of Cardiology, Norfolk \& Norwich Hospital, Norwich, UK

Correspondence to Dr Usha Rao, Cardiology SpR, Norfolk \& Norwich Hospital, Norwich NR4 7UY, UK; usha.rao@nnuh.nhs.uk

Competing interests None.

Provenance and peer review Not commissioned; internally peer reviewed. 
To cite Rao U, Freeman L. Heart Asia 2014;6:66-67. doi:10.1136/heartasia-2014-010535

Heart Asia 2014;6:66-67. doi:10.1136/heartasia-2014-010535

\section{REFERENCES}

1 Guttman FM, Laberge JM. Congenital diaphragmatic hernia. In: Nyhus LM, Condon RE, eds. Hernia. Philadelphia: JB Lippincott Company, 1989:694.

2 Comer TP, Clagett OT. Surgical treatment of hernia of the foramen of Morgagni. J Thorac Cardiovasc Surg 1966;52:461-8. 